\title{
Chapter 16 \\ NIRS's Project for the Reconstruction of Early \\ Internal Dose to Inhabitants in Fukushima After the Nuclear Disaster
}

\author{
Osamu Kurihara, Eunjoo Kim, Kumiko Fukutsu, Masaki Matsumoto, \\ Soheigh Suh, Keiichi Akahane, and Kazuo Sakai
}

\begin{abstract}
In 2012, National Institute of Radiological Sciences (NIRS) launched a project on the reconstruction of the early internal dose, namely the thyroid dose to inhabitants in Fukushima and adjacent prefectures from the intake of short-lived nuclides, mainly ${ }^{131} \mathrm{I}$ after the nuclear disaster. Limited human measurements make it difficult to estimate individual doses, and thus it is necessary to collect all information available and explore possible methods for dose reconstruction. As the first action of the project, a symposium was organized by NIRS on 10-11 July 2012. This chapter provides human or environmental measurement data collected and describes the current status of the project.
\end{abstract}

Keywords Dose reconstruction • Early internal dose • Fukushima • Inhabitants

- Nuclear disaster $\bullet$ Thyroid dose

\subsection{Introduction}

The Tokyo Electric Power Company (TEPCO) Fukushima Daiichi Nuclear Power Station (FDNPS) accident triggered by the Tohoku Region Pacific Coast Earthquake on 11 March 2011 resulted in reactor core meltdown with several hydrogen explosion events, following an enormous release of radioactive materials into the environment [1]. Airborne surveys after this nuclear disaster have shown the spatial distribution of ambient dose rates and the Cs ground deposition on a regional scale,

O. Kurihara $(\bowtie) \bullet$ E. Kim • K. Fukutsu • M. Matsumoto • S. Suh • K. Akahane • K. Sakai Research Center for Radiation Emergency Medicine, National Institute of Radiological Sciences, 4-9-1 Inage-ku, Chiba-City, Chiba 263-8555, Japan e-mail: osakuri@nirs.go.jp 
revealing that heavily contaminated areas were generated mainly in a northwesterly direction from FDNPS [2]. It is thus of great importance to understand the magnitude of individual doses to populations in affected areas from the aspect of foreseeing health effects attributed to radiation exposure in the accident. Preliminary dose estimations for inhabitants in Fukushima Prefecture and the whole of Japan have been reported by the World Health Organization (WHO) [3].

The Fukushima government has also initiated dose estimations of the inhabitants inside the prefecture and results obtained are described as follows. External dose estimations of 228,512 inhabitants have been completed as of the end of October 2012, demonstrating that $99.6 \%$ of these are $5 \mathrm{mSv}$ in effective dose for the first 4 months after the accident [4]. These estimations have been performed using a system for calculating individual external doses based on time-series maps of ambient dose rates in Fukushima Prefecture and personal behavior records. Human measurements of the inhabitants with whole-body counters (WBCs) have been performed for estimating their internal doses. It has been reported that 26 of 90,050 subjects exceeded $1 \mathrm{mSv}$ in the committed effective dose (CED) [5]. However, it should be noted that this result is for internal doses only from ${ }^{134} \mathrm{Cs}$ and ${ }^{137} \mathrm{Cs}$. The early internal dose, which is expected to be received by the intake of short-lived nuclides (e.g., ${ }^{131} \mathrm{I},{ }^{132} \mathrm{I},{ }^{132} \mathrm{Te}$ ) during the first few months after the accident, still remains unknown because of limited information available. Concern is thus raised concerning thyroid exposure to small children from the intake of radioiodine, as with situations found after Chernobyl accident [6].

In 2012, the National Institute of Radiological Sciences (NIRS) launched a project on the reconstruction of the early internal dose to the inhabitants in Fukushima and adjacent prefectures. As the first action of this project, the 1st NIRS symposium on "Reconstruction of early internal dose in the TEPCO Fukushima nuclear power station accident" was held on 10-11 July 2012. The main aims of this symposium were twofold: (1) to collect human and environmental measurement data available for estimating the early internal dose to the inhabitants and (2) to discuss methods for reconstructing the thyroid equivalent dose (hereinafter, thyroid dose) among invited experts from Japan and overseas. The proceedings of the symposium, including 17 peer-reviewed 17 papers and the summary of the discussion, have been published by NIRS [7]. Table 16.1 lists authors and titles of the papers included in the proceedings. The goals of the project this year are set as (1) to propose best methods for the internal dose estimation and (2) to estimate representative doses to the inhabitants of each area in Fukushima prefecture. This chapter briefly describes the current status of the project.

\subsection{Measurement Data Collection}

Main information on human and environmental measurements for reconstructing the thyroid dose to the inhabitants is described as follows. 
Table 16.1 Contents of the proceedings of the 1st NIRS symposium on reconstruction of early internal dose in the TEPCO Fukushima Daiichi nuclear power station accident [7]

Authors $\quad$ Title of paper

Part 1: Current status of internal does estimation

(1) For responders

C. Takada et al. Results of whole body counting for JAEA staff members engaged in the emergency radiological monitoring for the Fukushima nuclear disaster

O. Kurihara et al.

Direct measurements of employees involved in the Fukushima Daiichi nuclear power station accident for internal dose estimates: JAEA's experiences

T. Nakano et al. Direct measurements for highly-exposed TEPCO workers and NIRS first responders involved in the Fukushima NPS accident

N. Matuda et al. Retrospective assessment of internal doses for short-term visitors to Fukushima within 1 month after the nuclear power plant accident

M. Miyazaki et al. Lessons learned from early direct measurements at Fukushima medical university after the Fukushima nuclear power station accident

(2) For residents and visitors

S. Tokomami et al. Thyroid equivalent doses due to radioiodine-131 intake for evacuees from Fukushima Daiichi nuclear power plant accident

E. Kim et al.

Screening survey on thyroid exposure for children after the Fukushima Daiichi nuclear power station accident

T. Momose et al. Whole-body Counting of Fukushima residents after the TEPCO Fukushima Daiichi nuclear power station accident

I. Yamaguchi et al. Estimation of ingestion dose due to I-131 in the initial month by using food-monitoring data after the Fukushima nuclear disaster in Japan

Part 2: Measurement of radioactivity in the environment

H. Tsuruta Summary of atmospheric measurements and transport pathways of radioactive materials released by the Fukushima Daiichi nuclear power plant accident

T. Nakamura Radiation and radioactivity monitoring in the surrounding environment after the Fukushima Daiichi nuclear power plant accident-Overview

Part 3: Atmospheric dispersion simulations for radionuclides

M. Chino et al. Reconstruction of the atmospheric releases of ${ }^{131} \mathrm{I}$ and ${ }^{137} \mathrm{Cs}$ resulting from the Fukushima Daiichi nuclear power plant accident

H. Nagai et al. Atmospheric dispersion simulations of radioactive materials discharged from the Fukushima Daiichi nuclear power plant due to accident: consideration of deposition

T. Ohara and Y. Atmospheric transport and deposition modeling of radioactive materials: Morino current status and future tasks

G. Sugiyama et al. National atmospheric release advisory center dispersion modeling during the Fukushima Daiichi nuclear power plant accident

Part 4: Atmospheric dispersion simulations for radionuclides

M. Balonov and I. Methodology and results of internal dose reconstruction in Russia Zvonava after the Chernobyl accident: generic approach and thyroid dose

A. Bouville et al. Dose reconstruction related to the nuclear weapons tests conducted by the US in the Pacific in the 1950s 


\subsubsection{Human Thyroid Measurements}

Through the symposium, it was revealed that human thyroid measurement data of the inhabitants were much fewer in this accident compared to those collected in the Chernobyl accident. The total number of such measurements totals 1,500 at most; the largest dataset was a screening survey on the thyroid exposure that was conducted for 1,080 children in late March 2011 [8]. The subjects of this screening survey were inhabitants of Kawamata Town, Iwaki City, or Iitate Village where only indoor evacuation was advised because it was outside the restricted zone $(20-\mathrm{km}$ radius of FDNPS). The results demonstrated that net readings of the devices used in the screening survey were 0 for 598 of the 1,080 subjects and also suggested that no one had a thyroid dose that exceeded $100 \mathrm{mSv}$. Kim et al. [9] first introduced the thyroid dose distribution of the 1,080 subjects, showing that the maximum thyroid dose was $43 \mathrm{mSv}$ on the assumption of a chronic intake scenario. However, difficulty was recognized in evaluating the quantitative capability of the nonspectrometric devices being used under elevated levels of radiation background. On the other hand, Tokonami et al. [10] performed thyroid measurements with a $\mathrm{NaI}(\mathrm{Tl})$ scintillation spectrometer on 12-16 April 2011 of 62 subjects of Namie Town: 45 evacuees from coastal areas and 17 inhabitants in Tsushima district. Positive detection was found in 39 in the evacuees and 7 in the inhabitants. The maximum thyroid dose among the subjects was $23 \mathrm{mSv}$ in the group less than 20 years old and $33 \mathrm{mSv}$ in the group over 20 years old. Other human thyroid measurements were obtained from responders or workers in charge of emergency operations at FDNPS $[11,12]$.

\subsubsection{Human Whole-Body (WB) Measurements}

Although measurement data of WBCs directly give internal doses from Cs only, these data would be available for reconstructing the thyroid dose to the inhabitants if the intake ratio of I to Cs can be determined in some way. NIRS was in charge of the pilot survey as a part of Fukushima Health Management Survey [13]. This survey was performed for 122 inhabitants of pilot survey areas (Namie Town, Iitate Village, and Yamakiya district of Kawamata Town) from June 27 to July 16 in 2011 by means of the thyroid/WB measurements and urinalysis. Table 16.2 summarizes numbers of the subjects with positive detection in the thyroid/WB measurements. Only the WB measurements provided meaningful results, showing that neither ${ }^{134} \mathrm{Cs}$ nor ${ }^{137} \mathrm{Cs}$ was detected for about half the subjects. This result indicates that a median CED of the adult subjects was below $0.035 \mathrm{mSv}$, which was derived from the detection limit of the WB measurements based on an acute intake scenario via inhalation on 12 March 2011. The Japan Atomic Energy Agency (JAEA) subsequently started WB measurements of the inhabitants on 11 July 2011 at the request of the Fukushima government. The total number of the subjects (mainly children) reached 9,927 at the end of January in 2012. Momose et al. [14] have reported their analysis results of 
Table 16.2 Thyroid and whole-body measurement results of subjects of the pilot survey (as of 10 July 2011) [13]

\begin{tabular}{|c|c|c|c|c|c|c|c|c|c|c|}
\hline \multirow[b]{2}{*}{ Target nuclide } & \multicolumn{2}{|c|}{ 4-7 years } & \multicolumn{2}{|c|}{$8-12$ years } & \multicolumn{2}{|c|}{$13-17$ years } & \multicolumn{2}{|c|}{$\leq 18$ years } & \multicolumn{2}{|l|}{ All } \\
\hline & Pos. $^{a}$ & No. $^{b}$ & Pos. ${ }^{a}$ & No. $^{b}$ & Pos. $^{a}$ & No. $^{b}$ & Pos. ${ }^{a}$ & No. $^{b}$ & Pos. $^{a}$ & No. $^{b}$ \\
\hline${ }^{131} \mathrm{I}$ & 0 & 9 & 0 & 14 & 0 & 6 & 0 & 80 & 0 & 109 \\
\hline${ }^{134}$ Cs only & 2 & & 6 & & 2 & & 42 & & 52 & \\
\hline${ }^{137} \mathrm{Cs}$ only & 0 & & 0 & & 0 & & 32 & & 32 & \\
\hline${ }^{134} \mathrm{Cs}$ and ${ }^{137} \mathrm{Cs}$ & 0 & & 0 & & 0 & & 26 & & 26 & \\
\hline
\end{tabular}

Detection limits: $38 \mathrm{~Bq}$ for ${ }^{131} \mathrm{I}, 320 \mathrm{~Bq}$ for ${ }^{134} \mathrm{Cs}$, and $570 \mathrm{~Bq}$ for ${ }^{137} \mathrm{Cs}$

apositive detection

${ }^{\mathrm{b}}$ Subject number for each age group

the CED distributions of two age groups, 13-17 years old and older than 17 years. The median CED values of the two groups were evaluated to be 0.02 and $0.025 \mathrm{mSv}$, respectively. Here we note that all the individual CEDs were introduced based on the same intake scenario as described above for conservative estimations. Raw data of the WB measurements (e.g., the body content of Cs, measurement date, subject's age and sex, etc.) have not been published so far.

\subsubsection{Environmental Measurements}

Airborne sampling data are much needed because inhalation, rather than ingestion, is a main route of the intake by most of the inhabitants. However, such data were also rarely obtained in the first week after the accident. Continuous air sampling was performed only outside Fukushima Prefecture. Tsuruta et al. [15] have reported the gaseous/aerosol ratio of ${ }^{131} \mathrm{I}$ and the activity ratio of ${ }^{131} \mathrm{I} /{ }^{137} \mathrm{Cs}$ in air from their analyses on existing information. Both items are of importance for reconstructing the thyroid dose.

Figure 16.1 displays the relationship of the ${ }^{131} \mathrm{I}$ air concentration between gaseous and particulate forms at FDNPS, TPCO Fukushima Daini NPS (located $10 \mathrm{~km}$ south from FDNPS), and three sites of JAEA in Ibaraki Prefecture, showing that all the plots follow a common trend with a mean ratio of 0.5 in the ${ }^{131} \mathrm{I}$ concentration of higher than $10 \mathrm{~Bq} \mathrm{~m}^{-3}$. This ratio significantly influences thyroid dose values because the dose coefficient for inhalation of ${ }^{131} \mathrm{I}$ in the elemental form becomes doubled compared to that in the particulate form (Table 16.3) [16]. Although little analysis has been performed on the chemical form of iodine in the accident, most of the iodine was assumed to exist in the methylated state.

The activity ratio of ${ }^{131} \mathrm{I} /{ }^{137} \mathrm{Cs}$ also varied with time and location. This ratio changed significantly with two orders of magnitudes (1-100). It became around 10 on March 15 and March 20-21 when large releases of the nuclides from FDNPS occurred and was calculated as 8 from the average air concentrations of ${ }^{131} \mathrm{I}$ and ${ }^{137} \mathrm{Cs}$ at the site of the Nuclear Fuel Cycle Engineering Laboratories of JAEA 


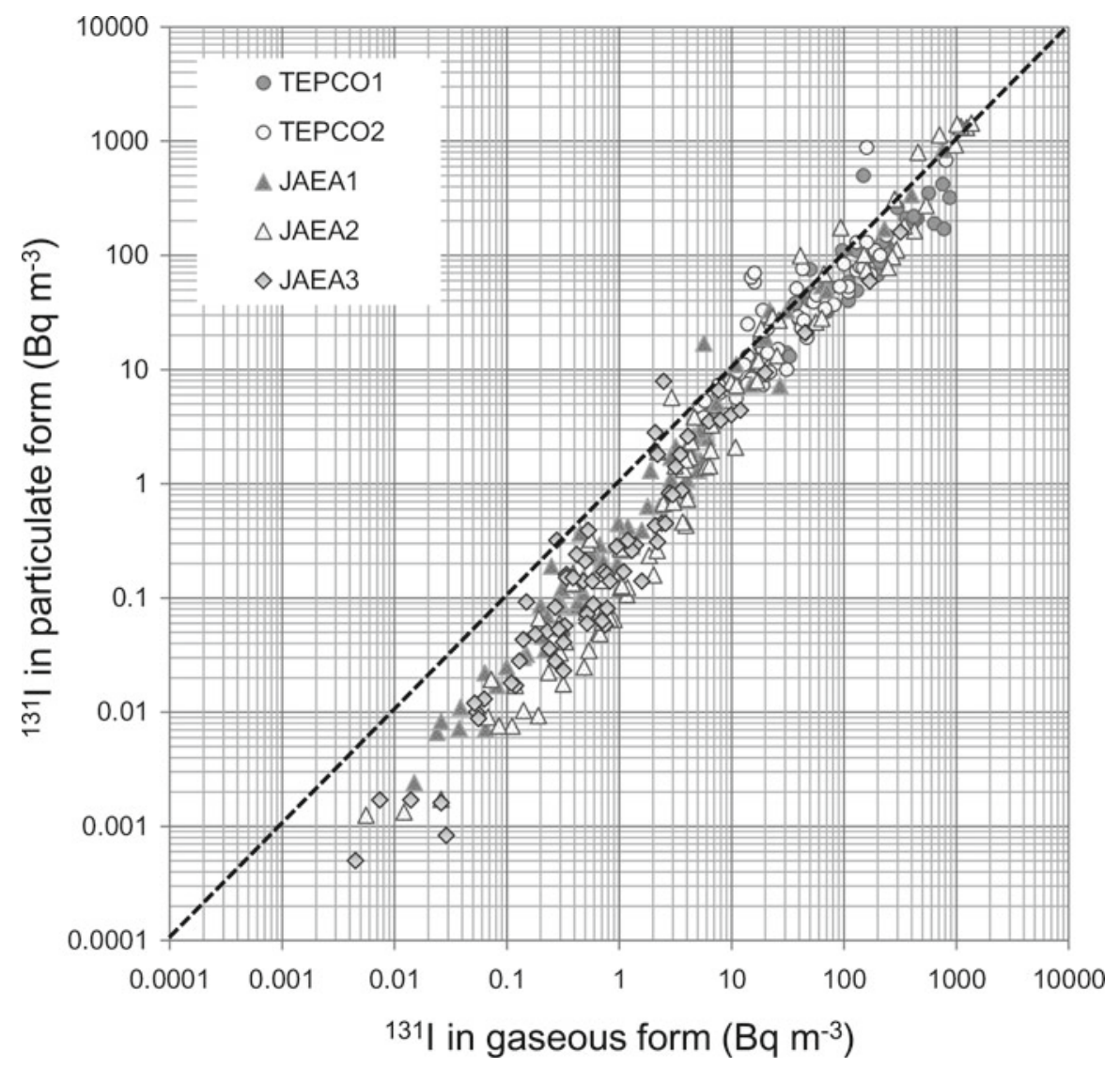

Fig. 16.1 Relationship of the physicochemical form of ${ }^{131} \mathrm{I}$ between gaseous and particulate forms. TEPCO1 Fukushima Daiichi nuclear power station, TEPCO2 Fukushima Daini nuclear power station

Table 16.3 Thyroid equivalent dose coefficient via inhalation for different age groups [16]

\begin{tabular}{lllllll}
\hline Physicochemical form & 3 months & 1 year & 5 years & 10 years & 15 years & Adult \\
\hline Methyl & $2.6 \mathrm{E}-06$ & $2.5 \mathrm{E}-06$ & $1.5 \mathrm{E}-06$ & $7.4 \mathrm{E}-07$ & $4.8 \mathrm{E}-07$ & $3.1 \mathrm{E}-07$ \\
Elemental & $3.3 \mathrm{E}-06$ & $3.2 \mathrm{E}-06$ & $1.9 \mathrm{E}-06$ & $9.5 \mathrm{E}-07$ & $6.2 \mathrm{E}-07$ & $3.9 \mathrm{E}-07$ \\
Particulate & $1.4 \mathrm{E}-06$ & $1.4 \mathrm{E}-06$ & $7.3 \mathrm{E}-07$ & $3.7 \mathrm{E}-07$ & $2.2 \mathrm{E}-07$ & $1.5 \mathrm{E}-07$ \\
\hline
\end{tabular}

Unit, $\mathrm{Sv} \mathrm{Bq}^{-1}$

(Table 16.4) [17]. These values seem to be consistent with a core inventory calculation. The activity ratio of ${ }^{131} \mathrm{I} /{ }^{137} \mathrm{Cs}$ on the ground surface shows a spatial distribution with higher ratios in a southerly direction and lower ratios in north and northwest directions from FDNPS, which is explained by the difference in metrological conditions at the time of the ground deposition. Details are described elsewhere. 
16 NIRS's Project for the Reconstruction of Early Internal Dose to Inhabitants...

Table 16.4 Dose contributions from various nuclides detected in air [17]

\begin{tabular}{|c|c|c|c|c|c|}
\hline \multirow[b]{2}{*}{ Nuclide } & \multirow{2}{*}{$\begin{array}{l}\text { Averaged air } \\
\text { concentration } \\
\left(\mathrm{Bq} \mathrm{m}^{-3}\right)^{\mathrm{a}}\end{array}$} & \multicolumn{2}{|c|}{ Adult (mSv) } & \multicolumn{2}{|c|}{ 1-year-old child (mSv) } \\
\hline & & $\begin{array}{l}\text { Effective } \\
\text { dose }\end{array}$ & $\begin{array}{l}\text { Thyroid } \\
\text { equivalent dose }\end{array}$ & $\begin{array}{l}\text { Effective } \\
\text { dose }\end{array}$ & $\begin{array}{l}\text { Thyroid } \\
\text { equivalent dose }\end{array}$ \\
\hline${ }^{129 \mathrm{~m}} \mathrm{Te}$ & 1.5 & $1.9 \mathrm{E}-02$ & $3.1 \mathrm{E}-02$ & $1.8 \mathrm{E}-02$ & $7.7 \mathrm{E}-02$ \\
\hline${ }^{132} \mathrm{Te}$ & 3.7 & $3.0 \mathrm{E}-02$ & $4.4 \mathrm{E}-01$ & $6.1 \mathrm{E}-02$ & 1.1 \\
\hline${ }^{131} \mathrm{I}$ & 12.0 & $3.8 \mathrm{E}-01$ & 7.4 & $7.0 \mathrm{E}-01$ & 14 \\
\hline${ }^{132} \mathrm{I}^{\mathrm{b}}$ & 3.7 & $1.8 \mathrm{E}-03$ & $2.1 \mathrm{E}-02$ & $3.1 \mathrm{E}-03$ & $5.1 \mathrm{E}-02$ \\
\hline${ }^{133} I$ & 0.56 & $3.6 \mathrm{E}-03$ & $6.8 \mathrm{E}-02$ & $8.5 \mathrm{E}-03$ & $1.7 \mathrm{E}-01$ \\
\hline${ }^{134} \mathrm{Cs}$ & 1.3 & $4.1 \mathrm{E}-02$ & $1.3 \mathrm{E}-02$ & $3.0 \mathrm{E}-02$ & $7.6 \mathrm{E}-03$ \\
\hline${ }^{136} \mathrm{Cs}$ & 0.21 & $9.0 \mathrm{E}-04$ & $3.2 \mathrm{E}-04$ & $8.2 \mathrm{E}-04$ & $2.9 \mathrm{E}-04$ \\
\hline${ }^{137} \mathrm{Cs}$ & 1.5 & $9.4 \mathrm{E}-02$ & $1.1 \mathrm{E}-02$ & $5.6 \mathrm{E}-02$ & $6.1 \mathrm{E}-03$ \\
\hline Total & & 0.57 & 7.9 & 0.88 & 15 \\
\hline
\end{tabular}

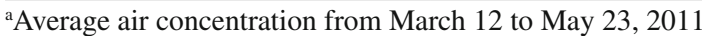

${ }^{\mathrm{b}}$ Assuming the equilibrium state with ${ }^{132} \mathrm{Te}$

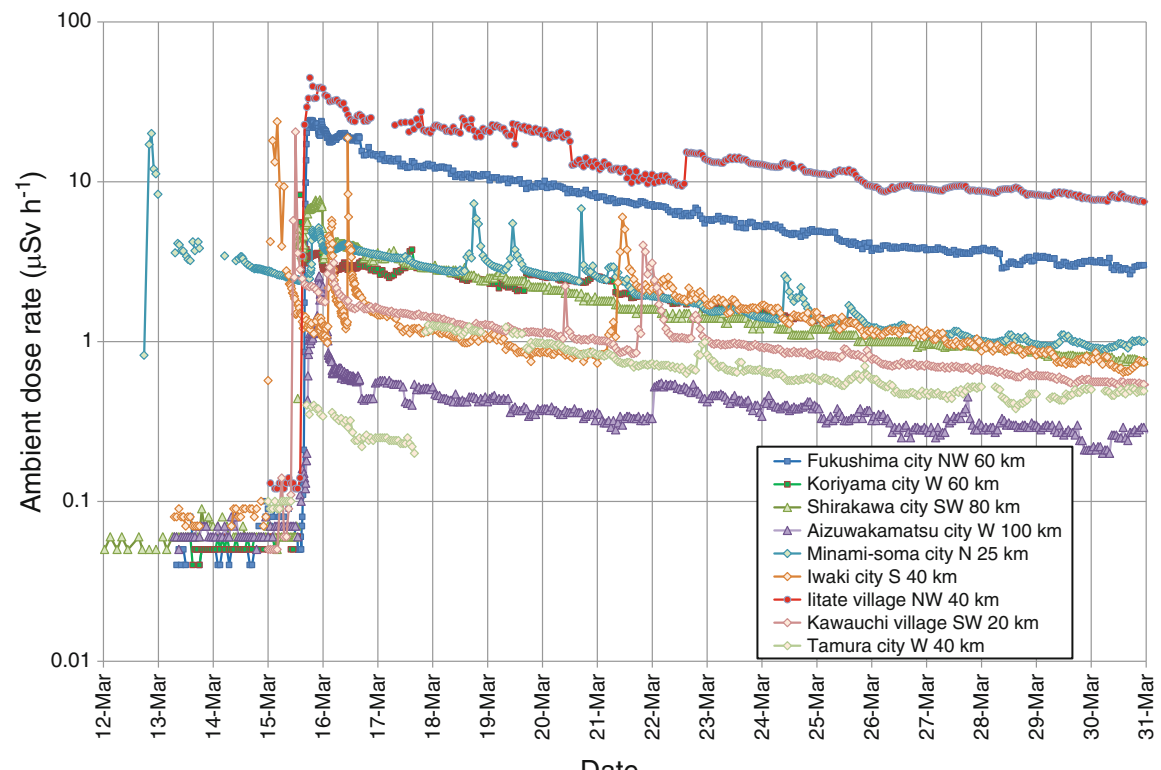

Fig. 16.2 Time trend of ambient dose rates at various locations in Fukushima Prefecture

Other short-lived nuclides such as ${ }^{132} \mathrm{I},{ }^{133} \mathrm{I}$, or ${ }^{132} \mathrm{Te}$ were observed in the air sampling at several locations $[17,18]$. Their contribution to the thyroid dose is estimated to be from $10 \%$ to $20 \%$, although this may vary with assumed physicochemical forms of the nuclides and an intake period of the evaluation.

Figure 16.2 displays trends of ambient dose rates at various locations in the Fukushima prefecture. The first peak appears on March 15 at most of the locations 
except for Minami-some city located north of FDNPS (on March 12). Thus, the first intake event for the inhabitants of the areas on the figure is also likely to occur on the same day. However, it is still difficult to know when and how the inhabitants, especially evacuees from the restricted zone, were exposed. Information on personal behavior records is needed: most of the evacuees moved outside the restricted zone before March 15. Atmospheric dispersion simulations for reproducing the behavior of enriched plumes may be also useful for this purpose.

\subsection{Proposed Methods}

Figure 16.3 displays proposed methods for reconstructing the thyroid dose to the inhabitants. The methods are classified into direct and indirect approaches: the former uses human data and the latter uses nonhuman data (including atmospheric dispersion simulations). The top priority in the dose reconstruction is placed on dose estimations from thyroid measurements. However, as mentioned earlier, such data are insufficient in terms of number and area. Thus, the direct approach utilizes available WB measurement data, which requires determining an appropriate intake ratio of I to Cs. Realistic scenarios of the intake are essential in the direct approach.

The dose estimation from the WB measurements is illustrated as follows. Here suppose the use of a CED value $\left({ }^{134} \mathrm{Cs}\right.$ and $\left.{ }^{137} \mathrm{Cs}\right)$ of the adult as the WB measurement data (currently available). Figure 16.4 displays a calculation flow from the CED of the adult to the thyroid doses to the children on the assumption that they both inhale the nuclides $\left({ }^{131} \mathrm{I}\right.$ and $\mathrm{Cs}$ ) with average ventilation rates for each age group under the same environment. The intake amounts of ${ }^{134} \mathrm{Cs}$ and ${ }^{137} \mathrm{Cs}$ giving a unit dose ( $1 \mathrm{mSv}$ in the CED) are calculated as $90,000 \mathrm{~Bq}$ for each; here the existing ratio of ${ }^{134} \mathrm{Cs} /{ }^{137} \mathrm{Cs}$ is set as equal. When the intake ratio of ${ }^{131} \mathrm{I} /{ }^{137} \mathrm{Cs}$ is 1 , the thyroid dose to the adult is $30 \mathrm{mSv}$, taking into account the gaseous/particulate ratio of ${ }^{131} \mathrm{I}$ and thyroid doses from nuclides other than ${ }^{131} \mathrm{I}$. The thyroid doses to a 1-year-old child and a 10-year-old child are also calculated as 60 and $50 \mathrm{mSv}$, respectively. Note that these thyroid doses increase in proportion to the intake ratio of ${ }^{131} \mathrm{I} /{ }^{137} \mathrm{Cs}$. For instance, when using a CED value of $0.025 \mathrm{mSv}$ (from the average CED for the adult inhabitants in Fukushima) and an intake ratio of 10 (from the average existing ratio in air at the JAEA site), the thyroid dose to the 1-year-old child is calculated as $15 \mathrm{mSv}(=0.025 \times 60 \times 10)$.

In the direct approach, internal doses received via inhalation or ingestion are separately estimated using materials on the figure. Dose estimation results from the indirect approach need to be compared with those from the direct approach for validation. 


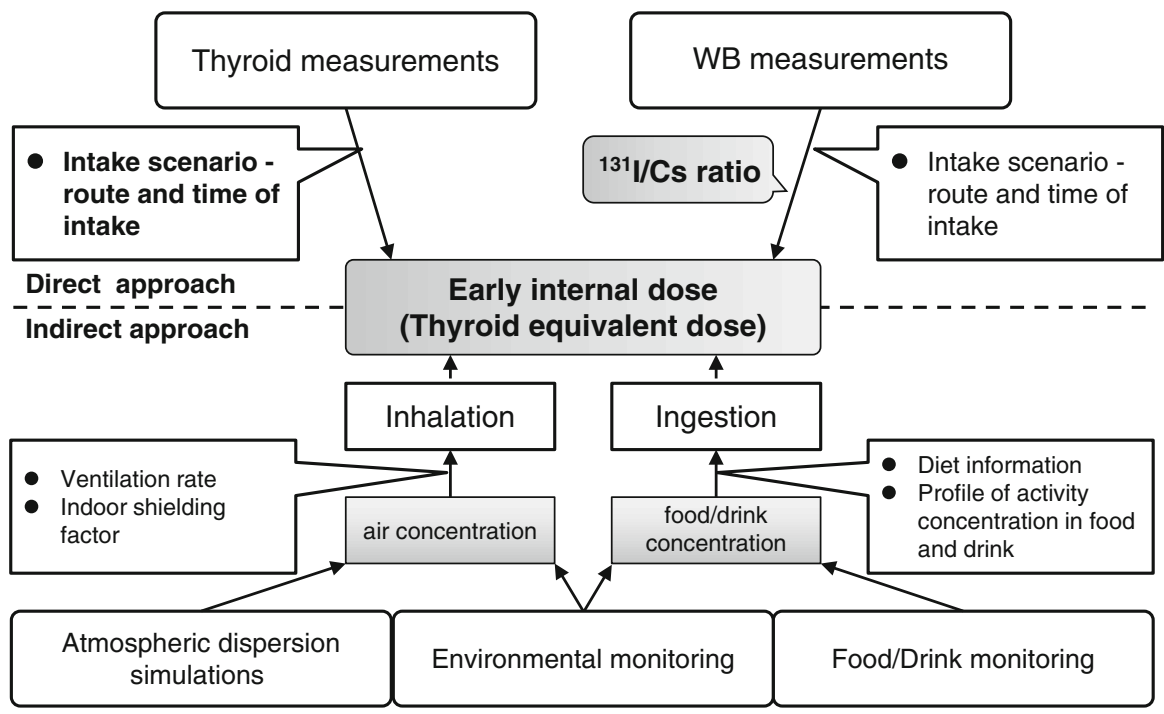

Fig. 16.3 Proposed methods for reconstruction of thyroid dose to inhabitants

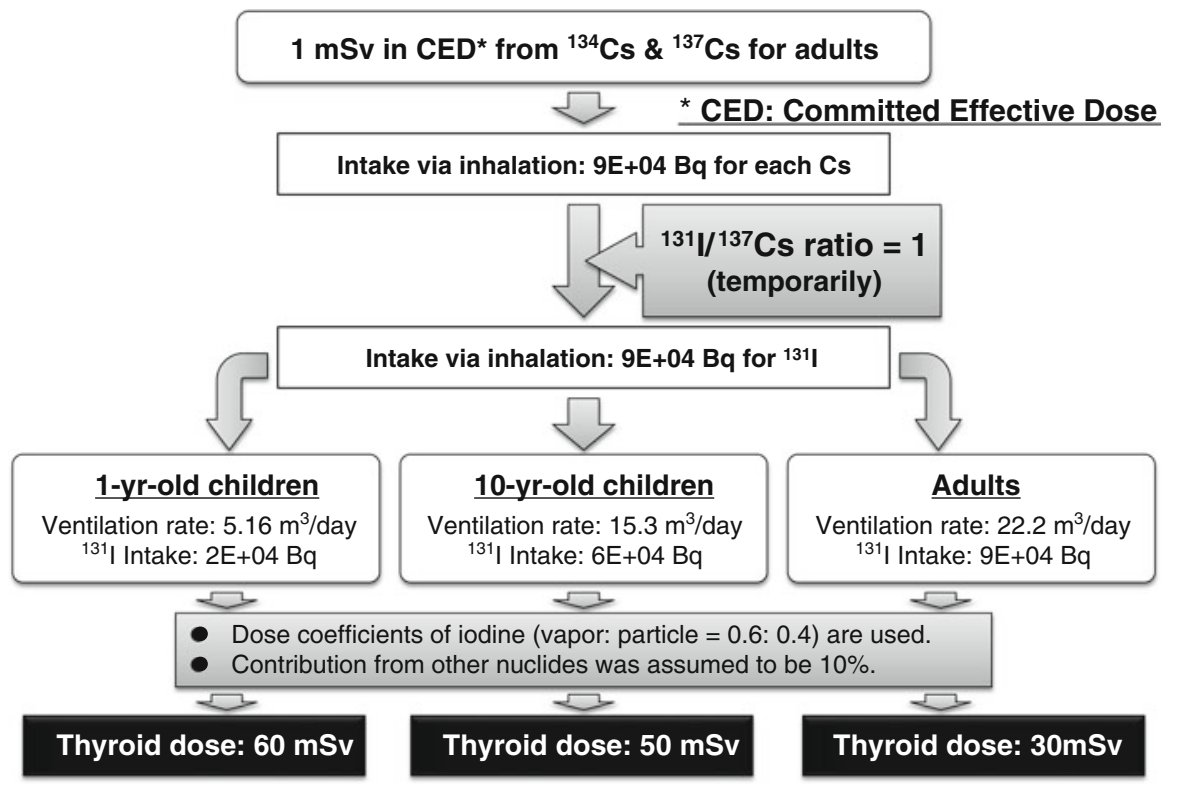

Fig. 16.4 Calculation flow of thyroid doses to different age groups from committed effective dose (CED) value of adult 


\subsection{Discussion and Future Tasks}

The project has just started. Thus, discussion is provided only on the feasibility of the proposed methods for dose reconstruction.

In the direct approach, the WB measurements would compensate a relativelysmall number of the thyroid measurements if appropriate intake ratios of ${ }^{131} \mathrm{I} / \mathrm{Cs}$ can be determined. From an inverse estimation by the System for Prediction of Environmental Emergency Dose Information (SPEEDI), the discharge amount ratio of ${ }^{131} \mathrm{I} /{ }^{137} \mathrm{Cs}$ resulted in 10 [19]. On the other hand, the ground deposition ratio of ${ }^{131} \mathrm{I} /{ }^{137} \mathrm{Cs}$ is found to significantly vary with location [20], which suggests that it is difficult to make use of the relationship between Cs ground deposition and the thyroid doses to inhabitants [21]. The WB measurements of early responders to the accident have shown that estimated intake ratios of ${ }^{131} \mathrm{I} / \mathrm{Cs}$ are considerably different between individuals [11]. Taking this fact into account, it would be necessary to carefully examine individual behavior.

In the indirect approach, the feasibility of atmospheric dispersion simulations for estimating the intake via inhalation is now under investigation. Figure 16.5 displays thyroid dose maps obtained from simulations by a worldwide version of SPEEDI (WSPEEDI-II) [22]. Note that these maps are given for hypothetical 1-year-old children and adults staying outside all the time from March 12 to March 31 in 2011. Thereby, these maps cannot be applied to persons moving during this period (e.g., the evacuees from the restricted zone), but would be useful for estimating thyroid doses to inhabitants on a regional scale. Preliminary calculations by WSPEEDI-II show reasonable overestimations for the thyroid dose in comparison to results of the
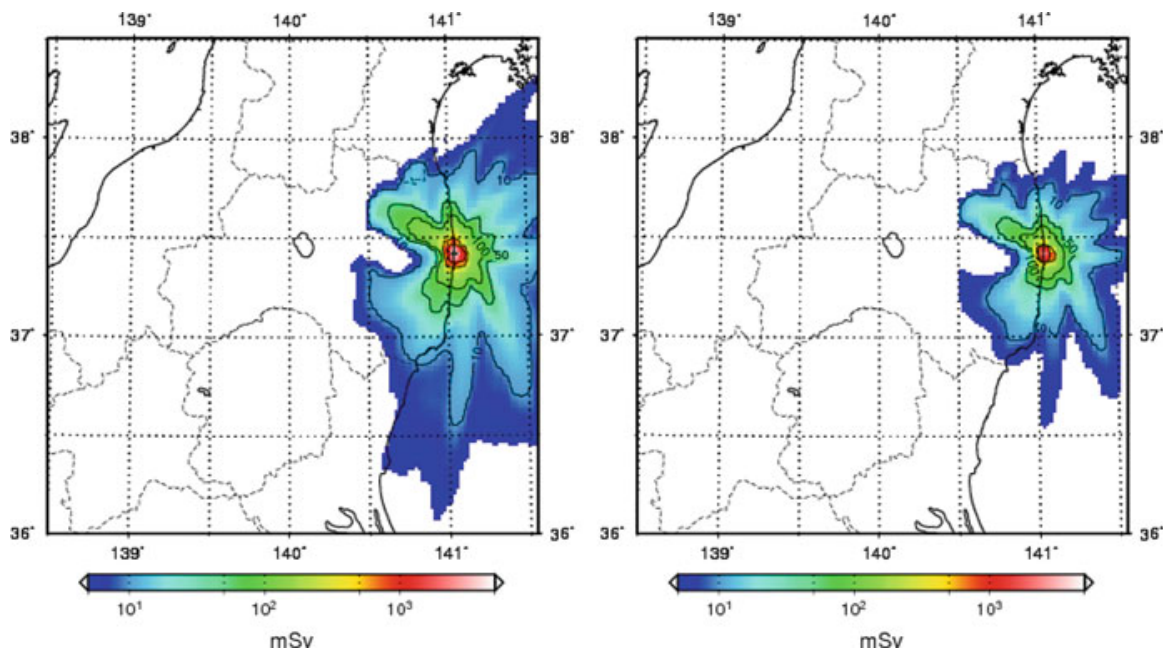

Fig. 16.5 Thyroid dose maps from inhalation of ${ }^{131}$ I from the simulation by WSPEEDI-II (period of intake, March 12-31) 
screening survey for the 1,080 children (data not shown here). Such a discrepancy would be minimized by adjusting parameters related to effects of indoor sheltering, a daily pattern of the ventilation rate, and so on.

Intake via ingestion in the accident is considered to be negligible for most of the inhabitants because of rapid action prohibiting the ingestion of contaminated food and water. In theory, the intake of the nuclides can be calculated using information on the diet intake and the concentration in food and water. However, this may not easy to perform. It is expected that the diet intake during the evacuation varies considerably from person to person and is more dependent on preserved foods than usual. Thereby, it is necessary to obtain information on the individual diet from personal interviews. This point was also stressed in the discussion of the last symposium.

Finally, future tasks for the dose reconstruction are listed as follows.

- To compile and validate all available data

- To track individual behavior for persons with human measurement data

- To analyze doses for each group with a similar behavior

- To determine appropriate intake ratios of ${ }^{131} \mathrm{I} / \mathrm{Cs}$

- To pursue investigations on the thyroid uptake of iodine in the Japanese

Acknowledgments This work has been conducted under the contract with Ministry of the Environment: Investigation on consequences of the nuclear disaster for 2012. Air concentration data from WSPEEDI-II were provided by Japan Atomic Energy Agency.

Open Access This article is distributed under the terms of the Creative Commons Attribution Noncommercial License which permits any noncommercial use, distribution, and reproduction in any medium, provided the original author(s) and source are credited.

\section{References}

1. Prime Minister of Japan and his Cabinet (2011) Report of Japanese government to the IAEA ministerial conference on nuclear safety: the accident at TEPCO's Fukushima nuclear power station [Internet]. http://www.kantei.go.jp/foreign/kan/topics/201106/iaea_houkokusho_e. html. Accessed 13 Nov 2013

2. Nuclear Regulation Authority [Internet]. http://radioactivity.nsr.go.jp/ja/list/258/list-1.html (in Japanese)

3. World Health Organization (2012) Preliminary dose estimation from the nuclear accident after the 2011 great East Japan earthquake and tsunami. World Health Organization. Geneva, Switzerland

4. Fukushima Prefecture [Internet] (2012) http://www.pref.fukushima.jp/imu/ kenkoukanri/241118kihontyosa.pdf (in Japanese). Accessed 13 Nov 2013

5. FukushimaPrefecture[Internet](2012)http://www.pref.fukushima.jp/imu/wbc/20121206wbc joukyou.pdf. (in Japanese). Accessed 13 Nov 2013

6. United Nations Scientific Committee on the Effects of Atomic Radiation (UNSCEAR) (2008) Health effects due to radiation from the Chernobyl accident. Source and effects of ionizing radiation, annex $\mathrm{J}$ 
7. National Institute of Radiological Sciences (NIRS). NIRS-M-252 the 1st NIRS symposium on reconstruction of early internal dose in the TEPCO Fukushima Daiichi nuclear power station accident [Internet]. http://repo.nirs.go.jp/dspace/bitstream/918273645/330/1/nirs_m_252.pdf

8. Fukushima I (2012) Results of simplified survey for thyroid internal exposure of children in Fukushima and other surveys. Jpn J Health Phys 47:17-19

9. Kim E, Kurihara O, Suzuki T, Matsumoto M, Fukutsu K, Yamada Y, Sugiura N, Akashi M (2012) Screening survey on thyroid exposure for children after the Fukushima Daiichi nuclear power station accident. NIRS-M-252, Chiba, Japan, pp 59-66

10. Tokonami S, Hosoda M, Akiba S, Sorimachi A, Kashiwakura I, Balonov M (2012) Thyroid doses for evacuees from the Fukushima nuclear accident. Sci Rep 2:507

11. Takada C, Kurihara O, Kanai K, Nakagawa T, Tsujimura N, Momose T (2012) Results of whole body counting for JAEA staff members engaged in the emergency radiological monitoring for the Fukushima nuclear disaster. NIRS-M-252, Chiba, Japan, pp 3-12

12. Matsuda N, Kumagai A, Otsuru A, Morita N, Miura M, Yoshida M, Kudo T, Takamura N, Yamashita S (2012) Retrospective assessment of internal doses for short-term visitors to Fukushima within one-month after the nuclear power plant accident. NIRS-M-252, Chiba, Japan, pp 35-39

13. Fukushima Prefecture [Internet]. http://www.pref.fukushima.jp/imu/kenkoukanri/230724 shiryou.pdf. (in Japanese)

14. Momose T, Takada C, Nakagawa T, Kanai K, Kurihara O, Tsujimura N, Ohi Y, Murayama T, Suzuki T, Uezu Y, Furuta S (2012) Whole-body counting of Fukushima residents after the TEPCO Fukushima Daiichi nuclear power station accident. NIRS-M-252, Chiba, Japan, pp $67-82$

15. Tsuruta H, Takigawa M, Nakajima T (2012) Summary of atmospheric measurements and transport pathways of radioactive materials released by the Fukushima Daiichi nuclear power plant accident. NIRS-M-252, Chiba, Japan, pp 101-111

16. International Commission on Radiological Protection (ICRP) (2001) The ICRP database of dose coefficients; workers and members of the public. Elsevier, New York

17. Takeyasu M, Nakano M, Fujita H, Nakada A, Watanabe H, Sumiya S, Furuta S (2012) Results of environmental radiation monitoring at the nuclear fuel cycle engineering laboratories, JAEA, following the Fukushima Daiichi nuclear power plant accident. J Nucl Sci Technol 49:281-286

18. Nagaoka K, Sato S, Araki S, Ohta Y, Ikeuchi Y (2012) Changes of radionuclides in the environment in Chiba, Japan after the Fukushima nuclear plant accident. Health Phys 102:437-442

19. Chino M, Nakayama H, Nagai H, Terada H, Katata G, Yamasawa H (2011) Preliminary estimation of release amounts of ${ }^{131} \mathrm{I}$ and ${ }^{137} \mathrm{Cs}$ accidentally discharged from the Fukushima Daiichi nuclear power plant into the atmosphere. J Nucl Sci Technol 48:1129-1134

20. Nuclear Regulation Authority [Internet] (2011) http://radioactivity.nsr.go.jp/ja/contents/6000/ 5047/24/5600_110921_rev130701.pdf (in Japanese). Accessed 13 Nov 2013

21. Balanov MI, Bruk GY, Zvonova IA, Pitkevich VA, Bratilova AA, Jesko TV, Shutov VN (2000) Methodology of internal dose reconstruction for a Russian population after the Chernobyl accident. Radiat Prot Dosim 92:247-253

22. Katata G, Terada H, Nagai H, Chino M (2012) Numerical reconstruction of high rate zones due to the Fukushima Dai-ichi nuclear power plant accident. J Environ Radioact 111:2-12 